\title{
ANTROPOSSOLOS EM SÍTIOS ARQUEOLÓGICOS DE AMBIENTE CÁRSTICO NO NORTE DE MINAS GERAIS ${ }^{(1)}$
}

\author{
Bruno Nery Fernandes Vasconcelos ${ }^{(2)}$, João Carlos Ker ${ }^{(3)}$, Carlos Ernesto Gonçalves \\ Reynaud Schaefer ${ }^{(3)}$, André Pierre Prous Poirier ${ }^{(4)}$ \& Felipe Vaz Andrade ${ }^{(5)}$
}

\begin{abstract}
RESUMO
A ocupação e a dispersão territorial dos primeiros colonizadores da América do Sul, sobretudo do Brasil, são ainda pouco conhecidas e exigem esforço interdisciplinar contínuo, envolvendo a antropologia, arqueologia e pedologia. Sob abrigos naturais de rochas calcárias, populações pré-colombianas viveram por milhares de anos, aportando e removendo matérias de naturezas e procedências distintas, desenvolvendo solos antropogênicos muito peculiares, sobre os quais ainda não se têm estudos pedológicos. Para melhor conhecer os solos, procedeu-se à caracterização física, química e mineralógica de solos de dois abrigos calcários, Lapas do Boquete e do Malhador, situados no Parque Nacional Cavernas do Peruaçu, norte de Minas Gerais, tido como uma das mais importantes regióes arqueológicas do país. As amostras foram submetidas à caracterização física, química e mineralógica, ao ataque total, à determinação do carbono orgânico total, além de fracionamento das formas inorgânicas de fósforo. As características químicas dos solos estudados estão condizentes com a natureza calcária da rocha local, apresentando valores de pH elevados $(>7,7)$. O complexo de troca catiônica é praticamente todo preenchido pelas bases trocáveis, principalmente $\mathrm{Ca}$ e $\mathbf{M g}$, alcançando valores de V de $100 \%$. Os teores de P-extraível (Mehlich-1) encontrados foram elevados, de 131 a $749 \mathrm{mg} \mathrm{dm}^{-3}$. Nos solos analisados, predominou a fração areia, sendo todas as camadas enquadradas na classe textural franco. É marcante a presença de óxidos com atração magnética em todas as frações, especialmente na fração areia, associada principalmente a camadas carbonizadas. Os solos apresentaram predomínio, em sua matriz, de minerais silicatados do tipo 1:1 (caulinita), associados a minerais do tipo 2:1, basicamente illita. De acordo com os
\end{abstract}

(1) Parte da Dissertação de Mestrado do primeiro autor apresentada ao Programa de Pós-Graduação em Solos e Nutrição de Plantas da Universidade Federal de Viçosa - UFV. Recebido para publicação em 26 de novembro de 2012 e aprovado em 6 de maio de 2013.

(2) Mestre em Solos e Nutrição de Plantas, DPS/UFV. E-mail: brunonery81@gmail.com

(3) Professor, Departamento de Solos - UFV. Av. P.H. Rolfs, s/n. CEP 36570-000 Viçosa (MG). E-mail: jker@ufv.br; carlos.schaefer@ufv.br

${ }^{(4)}$ Professor, Departamento de Sociologia e Antropologia, Universidade Federal de Minas Gerais. Caixa Postal 1275. Rua Gustavo da Silveira, 1.035, Santa Inês. CEP 31080-010 Belo Horizonte (MG). E-mail: aprous@dedalus.lcc.ufmg.br

(5) Professor, Departamento de Produção Vegetal, Universidade Federal do Espírito Santo. Alto Universitário, s/n. Caixa Postal 16. CEP 29500-000 Alegre (ES). E-mail: felipe.andrade@ufes.br 
resultados encontrados, os solos estudados apresentaram gênese policíclica, marcada por pronunciada alternância climática associada a distintos períodos de ocupação antrópica, que resultaram na formação de camadas aparentemente sem relação pedogenética entre si.

Termos de indexação: arqueoantropossolo, carste do Peruaçu, MG, caracterização química, fracionamento de $P$, maghemita.

\title{
SUMMARY: ANTHROSOLS AT ARCHAEOLOGICAL SITES IN A KARST ENVIRONMENT IN NORTHERN MINAS GERAIS
}

\begin{abstract}
The occupation and territorial dispersion of the first settlers in South America, especially in Brazil, are still little known and require continuous interdisciplinary studies involving anthropology, archeology, and soil science. Under natural limestone shelters, pre-Columbian populations lived for thousands of years, introducing and removing materials of different nature and from different origins, resulting in the development of very peculiar anthropogenic soils, which have been little investigated so far. To deepen the knowledge on this type of soil, we evaluated the physical, chemical and mineralogical properties of the soil of two limestone shelters, Lapa do Boquete and do Malhador, located in the National Park Cavernas do Peruaçu, in northern Minas Gerais, which is considered one of the most important archaeological regions of the country. The samples were subjected to the physical, chemical and mineralogical analyses, total attack, total organic carbon, and fractionation of inorganic $P$ forms. The chemical properties of these soils are consistent with the calcareous nature of the local rock, with high $\mathrm{pH}$ values (> 7.7). The cation exchange complex consists almost entirely of exchangeable bases, especially $C a$ and $M g$, reaching $V$ valuesof $100 \%$. High P contents (131-749 $\mathrm{mg} \mathrm{dm}^{-3}$ ) were also extracted (Mehlich-1). The predominant soil fraction was sand, with a loamy texture in all layers. The presence of oxides with magnetic attraction in all fractions is noteworthy, especially in the sand fraction, mainly associated with the carbonized layers. The soil matrix is made predominantly by 1:1 silicate minerals (kaolinite) associated with 2:1 minerals, mainly illite. According to the results, soil genesis is polycyclic, marked by pronounced climate changes, and associated with distinct periods of human occupation, resulting in the formation of pedogenetic layers that seem unrelated with each other.
\end{abstract}

Index terms: archeo-anthrosol; karst region Peruaçu, Minas Gerais, chemical characterization, $P$ fractionation; maghemite.

\section{INTRODUÇÃO}

A ocupação e a dispersão territorial dos primeiros colonizadores da América do Sul, principalmente do Brasil, são capítulos da história ainda pouco conhecidos. Compreender as origens, os costumes e a adaptabilidade ao ambiente dos povos pré-colombianos exigem esforço multidisciplinar. Nesse contexto, a pedologia se insere muito bem, uma vez que os solos representam verdadeiros corpos históricos, que preservam ao longo do tempo uma série de características resultante da interação entre as populações humanas e o ambiente onde viveram ou vivem (Kämpf \& Kern, 2005).

Solos profundamente modificados pela atividade humana com a incorporação de materiais orgânicos como estercos, urina, refugos domésticos, lama etc, são reconhecidos praticamente em todo o mundo, em que a atividade agrícola foi intensa e por longo tempo. Além de nomes regionais, são reconhecidos em nível categórico elevado, como Antrossolos ou Antropossolos pelo World Reference Base (FAO, 2006), ou fazem parte de solos com horizontes plaggen e antropic, como no Sistema Americano de Classificação de Solos (Soil Survey Staff, 1998).

No Brasil, existem três principais grupos de Antropossolos distribuídos em regiões diferentes do país, que são as Terras Pretas e Terras Mulatas de Indio, os solos desenvolvidos sobre Sambaquis e os sob abrigos calcários. Os mais expressivos são as Terras Pretas de Índio, que estão concentradas no norte do país, na região do rio Amazonas (Lima et al., 2002; Kern et al., 2003; Kämpf et al., 2003).

Outro ambiente onde se encontram solos de natureza antropogênica é no litoral do Brasil. Esses peculiares testemunhos arqueológicos deixados pelos povos précolombianos são denominados de Sambaquis ou concheiros e são datados de 8.000 até 2.000 anos AP (Prous, 1992). Um terceiro grupo de solos que apresenta influências antrópicas em sua formação são os solos encontrados em sítios arqueológicos sob abrigos calcários, onde as condições de $\mathrm{pH}$ mais elevado e restrição hídrica permitem maior preservação desse material. 
Os Antropossolos apresentam características físicas e químicas diversas, resultantes da deposição de restos e refugos de alimentos (ossos, vísceras, espinhas de peixes), excrementos humanos e de animais, cinzas de lenha queimada em fogueira, restos de cerâmicas e artefatos líticos; têm como uma das peculiaridades os teores elevados de $\mathrm{P}$, que não raramente ultrapassam $500 \mathrm{mg} \mathrm{kg}^{-1}$ (Kern \& Kämpf, 1989; Pabst, 1991; Lima et al., 2002; Silveira et al., 2002; Kern et al., 2003; Kämpf et al., 2003).

Diferentemente das Terras Pretas de Índio e dos Arqueoantropossolos de sambaquis, os solos de abrigo apresentam características morfológicas bastante diferentes como sequência de camadas sem relação pedogenética entre si; sem horizonte A antrópico que denote atividade agrícola local; e ausência de estrutura no material.

Objetivou-se com este trabalho caracterizar química, física e mineralogicamente dois perfis de solos localizados em área de abrigo indígena nas entradas das Lapas do Boquete e do Malhador, no Parque Nacional Cavernas do Peruaçu, Januária, MG.

\section{MATERIAL E MÉTODOS}

O Parque Nacional Cavernas do Peruaçu compreende uma área de 56.649 ha e localiza-se no norte de Minas Gerais à margem esquerda do altomédio rio São Francisco, entre os municípios de Januária e Itacarambi. No parque, é amplo o domínio de rochas calcárias do Grupo Bambuí, Proterozoico Superior, onde o relevo cárstico com muitas grutas e lapas propiciou o estabelecimento de população indígena há cerca de 12.000 anos (Prous, 2003). A vegetação na área é a Floresta Tropical Caducifólia, que inclui a Mata Seca nas áreas de solos rasos ou de afloramentos de calcário. A seleção das Lapas onde foram coletados os solos foi feita em conjunto com arqueólogos do Museu de História Natural da UFMG, objetivando coletar as amostras em locais onde já se tivessem realizadas escavações e houvesse informação arqueológica disponível, sobretudo quanto à datação de ocupação. Foram selecionadas duas Lapas (do Boquete e do Malhador) no Parque Nacional do Peruaçu (Figura 1).

Os materiais foram coletados em trincheiras previamente abertas em estudos arqueológicos, posteriormente foram secos e destorroados; quando necessário, passados em peneira com malha de $2 \mathrm{~mm}$ para obtenção da terra fina seca ao ar (TFSA) e submetidos às seguintes análises: granulométrica (Ruiz, 2005); químicas (Embrapa, 1997): pH em água e em $\mathrm{KCl} 1 \mathrm{~mol} \mathrm{~L}^{-1}$; P disponível, Na e K trocáveis (Mehlich-1), sendo o P determinado por espectrofotometria e o Na e K por fotometria de emissão de chama; Ca e Mg trocáveis por espectroscopia de absorção atômica e Al trocável por titulometria, após extração com KCl $1 \mathrm{~mol} \mathrm{~L}^{-1}$;
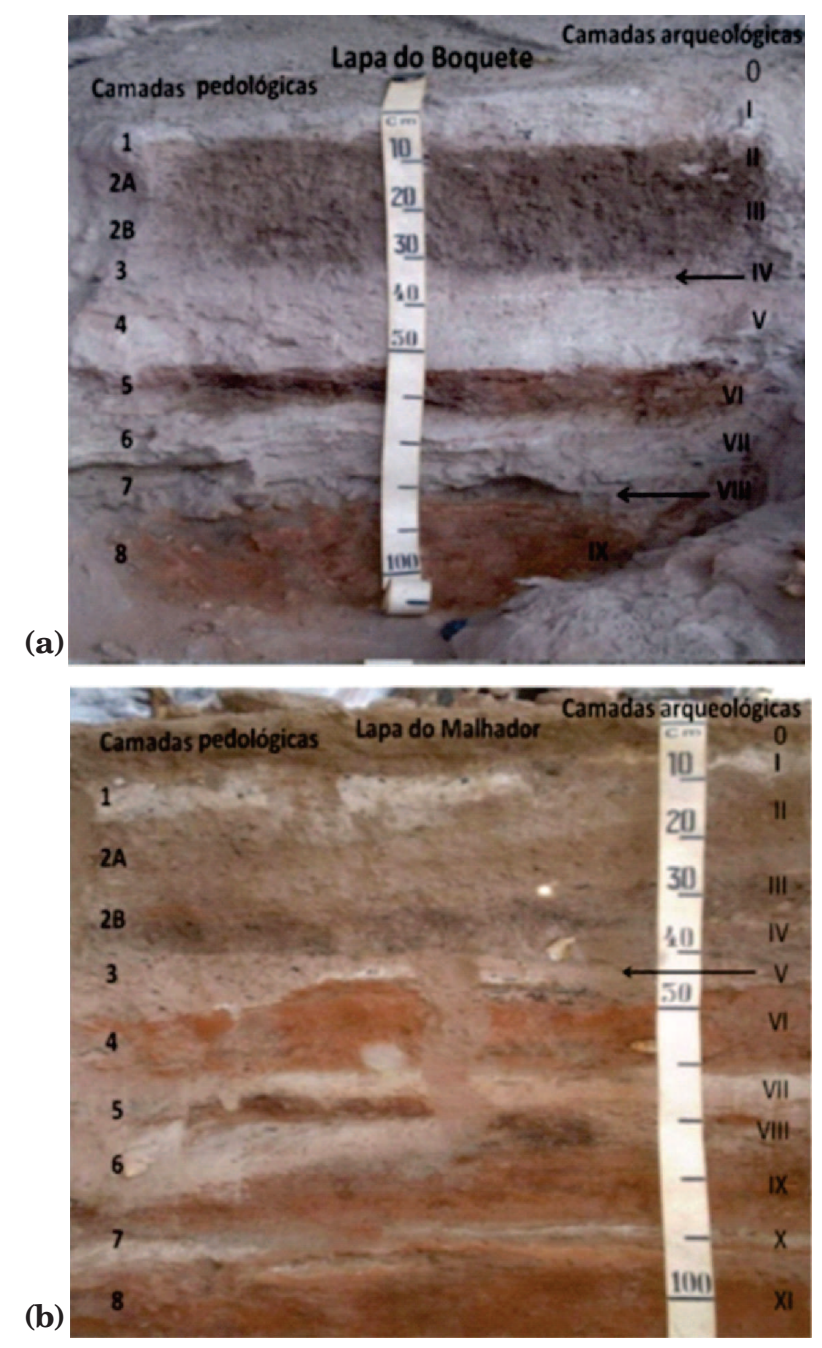

Figura 1. Perfis coletados dos solos das Lapas do Boquete (a) e do Malhador (b) no PARNA Cavernas do Peruaçu e a divisão das camadas, evidenciando as pedológicas e as arqueológicas.

acidez potencial $(\mathrm{H}+\mathrm{Al})$ por titulometria, após extração com $\mathrm{Ca}\left(\mathrm{CH}_{3} \mathrm{COO}\right)_{2} 0,5 \mathrm{~mol} \mathrm{~L}^{-1}$ a pH 7,0; P extraído com ácido cítrico (Soil Survey Staff, 1998) e determinado por espectrofotometria. O carbono orgânico total foi determinado segundo Yeomans \& Bremner (1998), com aquecimento em bloco digestor a $170{ }^{\circ} \mathrm{C}$ por $30 \mathrm{~min}$.

\section{Digestão Total}

Os extratos da digestão total foram obtidos da TFSA, utilizando $\mathrm{HNO}_{3}$ e $\mathrm{HF}$, ambos concentrados na proporção de 1:9 e 1:4, respectivamente, com aquecimento em forno de micro-ondas (Provecto Analítica DGT 100) nas potências de $450 \mathrm{~W}$, por 15 $\min ; 900 \mathrm{~W}$, por $25 \mathrm{~min}$; e $800 \mathrm{~W}$, por $15 \mathrm{~min}$, com $1 \mathrm{~h}$ de resfriamento e filtragem em papel-filtro lento, conforme método EPA 3052 (1996). Após esses procedimentos, foram determinados por espectrofotometria de emissão ótica de plasma 
(Perkinelmer - optima 3300 DV), indutivamente acoplados aos teores totais dos seguintes elementos: $\mathrm{Ca}, \mathrm{Mg}, \mathrm{K}, \mathrm{Fe}, \mathrm{Al}, \mathrm{Mn}, \mathrm{P}, \mathrm{Cr}, \mathrm{Zn}, \mathrm{Pb} \mathrm{Cd}, \mathrm{Cu}$ e Ba.

\section{Formas de P no Solo}

Foram determinadas as formas de fósforo no solo após extrações sequenciais, segundo Kelly et al. (1983). Utilizou-se $\mathrm{NH}_{4} \mathrm{Cl}$, com posterior agitação de 30 min e centrifugação, obtendo-se a fração de $\mathrm{P}$ disponível. Em seguida, $\mathrm{NH}_{4} \mathrm{~F}$, mais agitação de $1 \mathrm{~h}$, determinando-se a fração $\mathrm{P}$ associada ao $\mathrm{Al}$ ( $\mathrm{P}-\mathrm{Al})$. Após essa extração, o solo foi lavado com uma solução saturada de $\mathrm{NaCl}$ acrescentados $20 \mathrm{~mL}$ de $\mathrm{NaOH}$, que ficou sob agitação por $17 \mathrm{~h}$. Depois da centrifugação, a solução obtida recebeu $50 \mathrm{~mL}$ de $\mathrm{H}_{2} \mathrm{SO}_{4}$, foi agitada por mais $1 \mathrm{~h}$, obtendo-se o $\mathrm{P}$ ligado a ferro (P-Fe). $\mathrm{O}$ solo proveniente da agitação com $\mathrm{NaOH}$ também recebeu solução de $0,25 \mathrm{~mol} \mathrm{~L}^{-1}$ de $\mathrm{H}_{2} \mathrm{SO}_{4}$ e foi agitado por $1 \mathrm{~h}$, obtendo-se a fração de $\mathrm{P}$ associada ao cálcio ( $\mathrm{P}-\mathrm{Ca})$.

\section{Análises Mineralógicas}

Realizaram-se as análises mineralógicas nas frações argila e silte separadas por sedimentação e na fração areia separada por tamisação, conforme Embrapa (1997).

Para tanto, foram preparadas lâminas orientadas de argila natural e silte, utilizando-se a técnica do esfregaço. Para a fração areia, montaram-se lâminas escavadas não orientadas. A análise mineralógica foi realizada por difratometria de raios-X (DRX), com radiação $\mathrm{CoK} \alpha$, no intervalo entre 4 a $45^{\circ} 2 \theta$ (argila natural) e 5 a $30^{\circ} 2 \theta$ (argila com tratamento), com intervalos de $0,02{ }^{\circ} 2 \theta$ a 1 passo $\mathrm{s}^{-1}$, com tensão de $40 \mathrm{kV}$ e corrente de $30 \mathrm{~mA}$.

\section{RESULTADOS E DISCUSSÃO}

\section{Características Morfológicas e Físicas dos Solos}

Os solos das Lapas do Boquete e do Malhador são espessos, indicando atividade antrópica com maior deposição de material, resultado do maior tempo de ocupação, cerca de 12.800 anos AP (Prous, 1992).

Os solos estudados apresentaram marcante diferenciação de cor entre camadas (Quadro 1), indicando a inexistência de relação pedogenética entre elas, resultado da sua natureza deposicional policíclica. Não constatou-se estrutura, sendo todas as camadas constituídas de um material "pulverulento" que ao ser manuseado se desfaz com muita facilidade, lembrando cinza. É provável que o tempo, a não utilização agrícola, a pequena atividade biológica ( $\mathrm{pH}$ elevado), a falta de água para os ciclos de umedecimento e secagem (locais protegidos onde raramente a água de chuva exerce influência) tenham contribuíram para essa falta de agregação.

Nas camadas de número 8 dos solos das Lapas do Boquete e do Malhador, mais avermelhadas (Quadro 1), constatou-se estrutura moderada, pequena granular, indicando maior intemperização do material de origem, provavelmente numa condição climática mais úmida do que a atual (Moura,1998).

Nos solos analisados, predominou a fração areia, sendo todas as camadas enquadradas na classe textural franco ou em uma de suas derivações menos argilosas, principalmente franco-siltosa e francoarenosa (Quadro 1). O solo da Lapa do Malhador demonstra esse padrão, porém com teores de argila ligeiramente mais elevados, em relação ao da Lapa do Boquete. Nota-se, a partir dos resultados do quadro 1, uma tênue relação, nos solos dos abrigos, entre os maiores teores de argila e as camadas mais oxídicas, demonstrando a relação do maior grau de intemperismo nessas camadas com a formação de frações mais finas.

São elevados os teores de silte e areia dos solos (Quadro 1), condizentes com a textura de campo, ocasião em que a sedosidade dessa fração se destacava. Elevados também são os valores da relação silte/argila, reflexo do baixo estádio de intemperismo.

$\mathrm{Na}$ fração areia, encontra-se grande quantidade de conchas de gastrópodes terrestres da família Strophocheilideae, que são utilizadas como matériaprima para fabricação de instrumentos (Prous, 2003), carvão (fogueiras); e, em menor proporção, pequenas concreções ferruginosas com atração magnética, registro também da atividade antrópica pré-histórica ao longo de milênios (Prous, 2003).

\section{Características Químicas dos Solos}

Os valores de $\mathrm{pH}$ em $\mathrm{H}_{2} \mathrm{O}$ são elevados em todas as camadas, sendo o menor valor 7,7 na quinta camada do solo da Lapa do Boquete (Quadro 2), o que corrobora com a natureza calcária do material de origem (calcários do grupo Bambuí). O aporte de cinzas, provenientes da queima de materiais orgânicos (fogueiras) ao longo de milhares de anos, encontradas no piso dos abrigos, além de outros resíduos orgânicos, como restos vegetais e animais não provenientes da queima, também contribuem para esses elevados valores de $\mathrm{pH}$.

Segundo Parsons (1962), citado por Woods (2003), o $\mathrm{pH}$ é utilizado em estudos arqueológicos para distinguir níveis de ocupação e diferentes zonas estratigráficas, além de auxiliar na identificação de possíveis distúrbios ocorridos nos pacotes estratigráficos. O solo da Lapa do Boquete apresentou variação nos valores de $\mathrm{pH}$, a partir da quinta camada: 7,$7 ; 8,3 ; 8,2$; e 8,0 (Quadro 2).

O complexo de troca dos solos é saturado por $\mathrm{Ca}^{2+}$ e $\mathrm{Mg}^{2+}$, refletindo a influência do material de origem. Os valores de saturação por bases (V) atingem $100 \%$ 
Quadro 1. Características físicas e morfológicas dos perfis de solos estudados

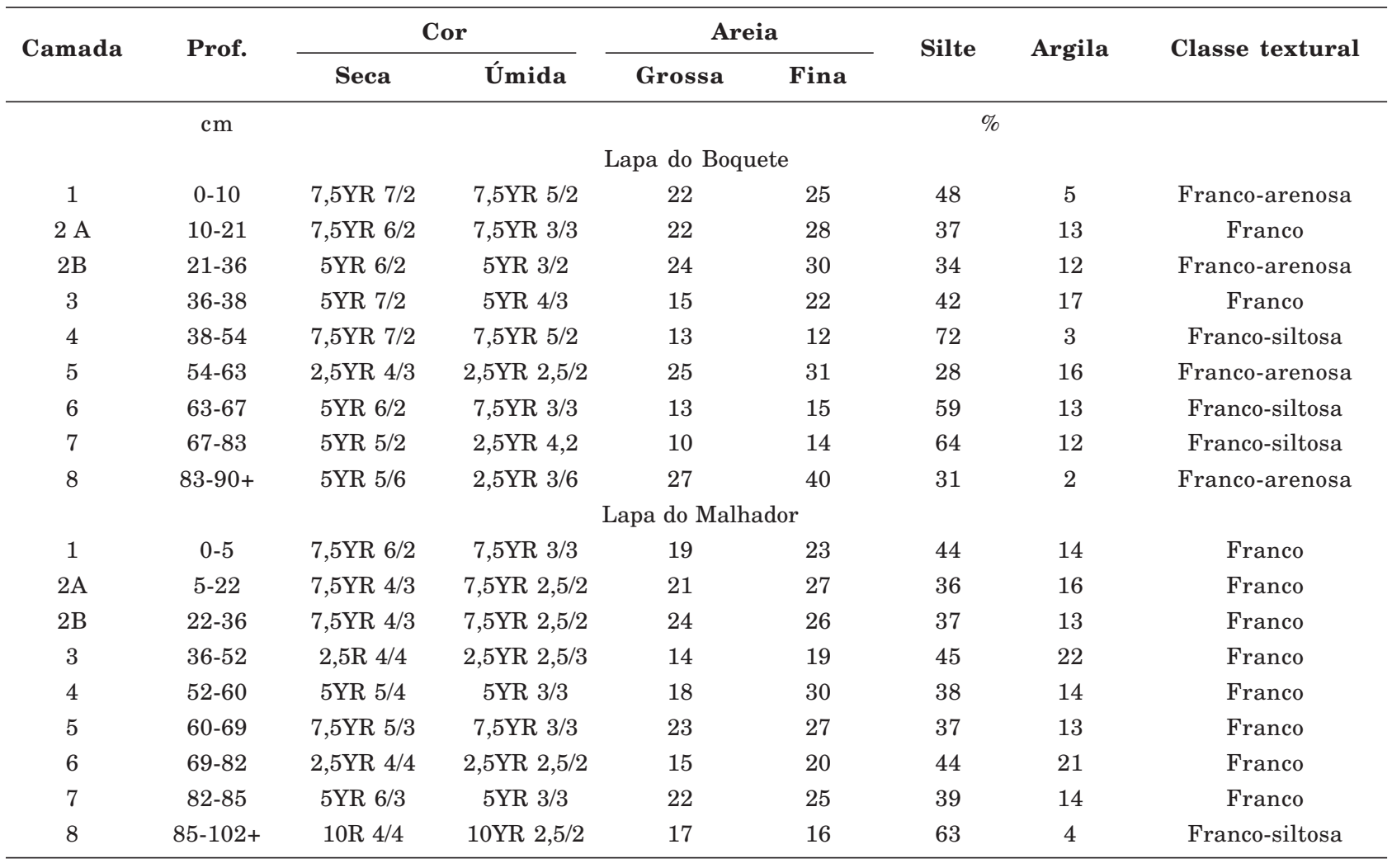

Quadro 2. Características químicas dos perfis de solos das Lapas do Boquete e do Malhador

\begin{tabular}{|c|c|c|c|c|c|c|c|c|c|c|c|c|c|c|c|c|c|}
\hline \multirow{2}{*}{ Camada } & \multirow{2}{*}{ Prof. } & \multicolumn{2}{|c|}{ pH } & \multicolumn{9}{|c|}{ Complexo sortivo } & \multirow{2}{*}{$\mathbf{P}$} & \multirow{2}{*}{$\mathbf{P}^{(1)}$} & \multirow{2}{*}{$\mathbf{v}$} & \multirow{2}{*}{$\mathbf{m}$} & \multirow{2}{*}{ COT } \\
\hline & & $\mathrm{H}_{2} \mathrm{O}$ & KCl & $\mathbf{C a}^{2+}$ & $\mathbf{M g}^{2+}$ & $\mathbf{K}^{+}$ & $\mathbf{N a}^{+}$ & SB & Al & $\mathbf{H}+\mathbf{A l}$ & CTCe & $\mathbf{T}$ & & & & & \\
\hline $\mathrm{cm}$ & $\mathrm{cm}$ & & & \multicolumn{9}{|c|}{$-\mathrm{cmol}_{\mathrm{c}} \mathrm{dm}^{-3}$} & \multirow{2}{*}{\multicolumn{2}{|c|}{$-\mathrm{mgdm} \mathrm{dm}^{-3}-$}} & \multicolumn{2}{|c|}{$-\%$} & dag $\mathrm{kg}^{-1}$ \\
\hline \multicolumn{17}{|c|}{ Lapa do Boquete } & \\
\hline $1^{\mathrm{a}}$ & $0-10$ & 9,7 & 9,1 & 0,93 & 0,62 & 26,67 & 0,57 & 28,73 & 0,0 & 0,0 & 28,73 & 28,73 & 176,3 & 370,73 & 100 & 0,0 & 0,93 \\
\hline $2 \mathrm{~A}$ & $10-21$ & 9,1 & 8,2 & 3,42 & 3,86 & 8,00 & 0,29 & 15,55 & 0,0 & 0,0 & 15,55 & 15,55 & 254,2 & 794,08 & 100 & 0,0 & 4,16 \\
\hline $2 \mathrm{~B}$ & $21-36$ & 9,0 & 7,9 & 5,07 & 3,08 & 2,60 & 0,26 & 11,01 & 0,0 & 0,0 & 11,01 & 11,01 & 234,0 & 646,36 & 100 & 0,0 & 3,68 \\
\hline $3^{\mathrm{a}}$ & $36-38$ & 9,2 & 8,5 & 2,98 & 1,69 & 1,90 & 0,23 & 6,80 & 0,0 & 0,0 & 6,80 & 6,80 & 180,7 & 467,67 & 100 & 0,0 & 1,39 \\
\hline $4^{\mathrm{a}}$ & $38-54$ & 8,9 & 8,2 & 2,34 & 1,28 & 1,06 & 0,22 & 4,90 & 0,0 & 0,0 & 4,90 & 4,90 & 155,1 & 283,07 & 100 & 0,0 & 0,51 \\
\hline $5^{\mathrm{a}}$ & $54-63$ & 7,7 & 7,7 & 13,38 & 9,52 & 2,11 & 0,34 & 25,35 & 0,0 & 0,0 & 25,35 & 25,35 & 629,7 & 3016,25 & 100 & 0,0 & 5,25 \\
\hline $6^{\mathrm{a}}$ & $63-67$ & 8,3 & 7,9 & 4,32 & 2,26 & 1,11 & 0,27 & 7,96 & 0,0 & 0,0 & 7,96 & 7,96 & 297,5 & 595,86 & 100 & 0,0 & 0,97 \\
\hline $7^{\mathrm{a}}$ & $67-83$ & 8,2 & 7,9 & 6,94 & 3,31 & 1,38 & 0,40 & 12,03 & 0,0 & 0,0 & 12,03 & 12,03 & 427,8 & 821,78 & 100 & 0,0 & 2,59 \\
\hline $8^{\mathrm{a}}$ & $83-90+$ & 8,0 & 7,9 & 18,42 & 2,43 & 1,15 & 0,44 & 22,44 & 0,0 & 0,0 & 22,44 & 22,44 & 749,0 & 3724,32 & 100 & 0,0 & 1,22 \\
\hline \multicolumn{18}{|c|}{ Lapa do Malhador } \\
\hline $1^{\mathrm{a}}$ & $0-5$ & 8,6 & 8,4 & 4,23 & 1,13 & 14,15 & 0,44 & 19,87 & 0,0 & 0,0 & 19,87 & 19,87 & 240,5 & 333,83 & 100 & 0,0 & 2,16 \\
\hline $2 \mathrm{~A}$ & $5-22$ & 8,3 & 7,9 & 8,20 & 2,24 & 13,53 & 0,21 & 24,15 & 0,0 & 0,0 & 24,15 & 24,15 & 259,1 & 1538,98 & 100 & 0,0 & 3,54 \\
\hline $2 \mathrm{~B}$ & $22-36$ & 9,1 & 7,8 & 5,30 & 1,99 & 3,33 & 0,26 & 10,87 & 0,0 & 0,0 & 10,87 & 10,87 & 131,7 & 389,13 & 100 & 0,0 & 2,83 \\
\hline $3^{\mathrm{a}}$ & $36-52$ & 8,2 & 7,8 & 9,34 & 1,90 & 0,6 & 0,22 & 12,04 & 0,0 & 0,0 & 12,04 & 12,04 & 549,2 & 2169,03 & 100 & 0,0 & 1,32 \\
\hline $4^{\mathrm{a}}$ & $52-60$ & 8,7 & 8,0 & 6,98 & 1,80 & 3,84 & 0,28 & 12,89 & 0,0 & 0,0 & 12,89 & 12,89 & 255,8 & 482,92 & 100 & 0,0 & 2,85 \\
\hline $5^{\mathrm{a}}$ & $60-69$ & 8,8 & 8,0 & 7,55 & 2,25 & 1,33 & 0,26 & 11,38 & 0,0 & 0,0 & 11,38 & 11,38 & 327,7 & 751,80 & 100 & 0,0 & 2,59 \\
\hline $6^{\mathrm{a}}$ & $69-82$ & 8,3 & 7,8 & 9,45 & 2,06 & 4,46 & 0,22 & 16,18 & 0,0 & 0,0 & 16,18 & 16,18 & 200,6 & 534,51 & 100 & 0,0 & 2,26 \\
\hline $7^{\mathrm{a}}$ & $82-85$ & 8,8 & 7,8 & 3,89 & 1,30 & 3,00 & 0,35 & 8,48 & 0,0 & 0,0 & 8,48 & 8,48 & 347,1 & 704,49 & 100 & 0,0 & 2,35 \\
\hline $8^{\mathrm{a}}$ & $85-102$ & 8,0 & 7,6 & 11,93 & 1,85 & 5,38 & 0,32 & 19,47 & 0,0 & 0,0 & 19,47 & 19,47 & 471,8 & 954,06 & 100 & 0,0 & 0,78 \\
\hline
\end{tabular}

SB: soma de bases trocáveis; CTCe: CTC efetiva; T: CTC a pH 7,0; ${ }^{(1)} \mathrm{P}: \mathrm{P}$ extraído com ácido cítrico; V: saturação por bases; m: saturação por alumínio; e COT: carbono orgânico total. 
em todas as camadas dos solos das Lapas do Boquete e do Malhador.

Os valores de carbono orgânico total (COT) nos solos estudados são variáveis ao longo do perfil, tendose valores elevados intercalados com os mais baixos, novamente sem obedecer a uma sequência pedogenética normal o que confirma a influência cíclica da atividade antrópica ("antropoturbação/ pedoturbação") das populações pré-colombianas, na gênese desses solos, pois se encontram em camadas profundas teores de materiais orgânicos mais elevados do que nas camadas sobrejacentes.

Os teores de $\mathrm{P}$ disponível (P-Mehlich-1) foram elevados (de 131 a $749 \mathrm{mg} \mathrm{dm}^{-3}$ ), variando ao longo do perfil, e sempre menores do que aqueles extraídos com ácido cítrico (Quadro 1), referência para caracterização de Antropic horizon do Sistema Americano de Classificação de Solos (Soil Survey Staff, 1998). O P é um elemento presente na urina, nas fezes, em tecidos vegetais e animais e, em maior quantidade, nos ossos (Woods, 2003), o que explica os valores elevados desse elemento nos solos estudados e confirma porque o P é um dos elementos-chave na caracterização de Antropossolos. Assim, onde houve ocupação antrópica, tais materiais foram aportados, propiciando o acúmulo de $\mathrm{P}$ no ambiente ao longo do tempo. Nos solos deste estudo, o P está predominantemente ligado ao cálcio (P-Ca) (Quadro 3).

Nem toda a fonte de $\mathrm{P}$ é proveniente de aporte antrópico. No caso dos solos de abrigos calcários, um fator que parece contribuir para o incremento desse elemento são as fezes de animais como aves, morcegos e pequenos roedores (Mocó e Preá), que frequentam ou ocupam esses abrigos.

Quadro 3. Fracionamento das formas inorgânicas de fósforo: $\mathrm{P}$ ligado a alumínio (P-Al), $\mathrm{P}$ ligado a ferro ( $P$-Fe) e $P$ ligado a cálcio $(P-C a)$ de camadas selecionadas de alguns dos horizontes ou camadas das Lapas do Boquete e do Malhador

\begin{tabular}{|c|c|c|c|c|}
\hline Camada & Prof. & P-Al & P-Fe & P-Ca \\
\hline & $\mathrm{cm}$ & 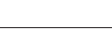 & $\mathrm{ng} \mathrm{dm}^{-}$ & \\
\hline \multicolumn{5}{|c|}{ Lapa do Boquete } \\
\hline $2 \mathrm{~A}$ & $10-21$ & 14,84 & 0,00 & $1.846,98$ \\
\hline 5 & $54-63$ & 574,92 & 0,00 & $1.909,44$ \\
\hline 6 & $63-67$ & 0,00 & 0,00 & $6.752,59$ \\
\hline 7 & $67-83$ & 24,57 & 0,00 & $6.416,83$ \\
\hline 8 & $83-90$ & 769,54 & 0,00 & $3.423,46$ \\
\hline \multicolumn{5}{|c|}{ Lapa do Malhador } \\
\hline 1 & $0-5$ & 30,06 & 0,00 & $2.678,30$ \\
\hline $2 \mathrm{~B}$ & $22-36$ & 111,13 & 0,00 & $2.719,53$ \\
\hline 3 & $36-52$ & 517,72 & 0,00 & $1.430,23$ \\
\hline 7 & $82-85$ & 64,71 & 0,00 & $3.922,80$ \\
\hline 8 & $85-102$ & 159,70 & 0,00 & $3.944,51$ \\
\hline
\end{tabular}

\section{Fracionamento de Fósforo}

A natureza calcária do material originário dos solos, os elevados valores de $\mathrm{pH}$, o prolongado período em que o material permanece dessecado e o fato de que as formas de $\mathrm{P}$ ligado a $\mathrm{Ca}(\mathrm{P}-\mathrm{Ca})$ são as de liberação mais lenta de P (Novais \& Smyth, 1999), quando comparada à formas de $\mathrm{P}-\mathrm{Fe}$ e $\mathrm{P}-\mathrm{Al}$, conferem um ambiente de excelente conservação das formas primárias de $\mathrm{P}$ ligadas ao cálcio (Quadro 3).

Os valores de $\mathrm{P}-\mathrm{Ca}$ encontrados variaram de $1.430,23 \mathrm{mg} \mathrm{dm}^{-3}$, na camada 3 da Lapa do Malhador, a $6.752,59 \mathrm{mg} \mathrm{dm}^{-3}$, na camada 6 da Lapa do Boquete. Além do aporte dos refugos animais incorporados ao solo, os elevados valores de P-Ca estão também associados com a formação de fosfatos de cálcio secundários (fosfatos mono e bicálcicos), cuja solubilidade decresce com o aumento do pH. Esses valores são bem mais elevados do que os encontrados por Lima (2002), que realizou o fracionamento de $\mathrm{P}$ em amostras de Terra Preta de Índio (solos ácidos) da região Amazônica, evidenciando o contraste entre as condições conservadoras encontradas nos sítios sob abrigos calcários e o ambiente ácido e úmido, encontrado na floresta Amazônica.

\section{Digestão Total}

Os valores de $\mathrm{P}_{2} \mathrm{O}_{5}$, em média, são maiores na Lapa do Boquete, especialmente nas camadas mais profundas (Quadro 4), o que remete a uma maior intensidade de ocupação nos períodos mais antigos (12.000 a 8.000 anos AP), quando grupos paleoíndios, do Holoceno inferior ao médio, ocuparam a região (Neves et al., 2009).

A camada 8 do solo da Lapa do Malhador apresentou valor baixo de $\mathrm{CaO}\left(0,94 \mathrm{dag} \mathrm{kg}^{-1}\right)$ e mais elevado de $\mathrm{Fe}_{2} \mathrm{O}_{3}\left(5,70\right.$ dag kg-1) e de $\mathrm{Al}_{2} \mathrm{O}_{3}(3,93$ dag kg-1) (Quadro 4), sugerindo condições paleoambientais mais úmidas ou acúmulo de materiais oxídicos utilizados como pigmentos pelas populações pré-históricas que ocuparam esses abrigos.

Dentre os elementos-traço, destacaram-se os valores encontrados para $\mathrm{Zn}$ e $\mathrm{Cu}$, ambos associados com excretas humanas, sendo o $\mathrm{Zn}$ mais presente nas fezes e nos ossos e o Cu, na urina (Woods, 2003). O Zn apresentou valores médios de $120 \mathrm{mg} \mathrm{kg}^{-1}$, que estão dentro dos valores de referência determinados pela Companhia de Tecnologia de Saneamento Ambiental do Estado de São Paulo (CETESB, 2005) como indicativos de qualidade ambiental, que variam de 1 a $200 \mathrm{mg} \mathrm{kg}^{-1}$. Oliveira (1999) constatou em solos da região teores de $\mathrm{Zn}$ que variaram de 8 a $59 \mathrm{mg} \mathrm{kg}^{-1}$. Corrêa (2007) encontrou teores desse elemento que variaram de 15 a $172 \mathrm{mg} \mathrm{kg}^{-1}$, em solos sob sambaquis na região dos Lagos no Estado do Rio de Janeiro, estando os maiores valores associados aos horizontes que tiveram maior influência da atividade antrópica.

Os resultados que se encontram no quadro 4 demonstram claramente a dificuldade de compreender 
Quadro 4. Teores de óxidos e elementos-traço determinados após digestão total da TFSA(1) dos solos das Lapas do Boquete e do Malhador

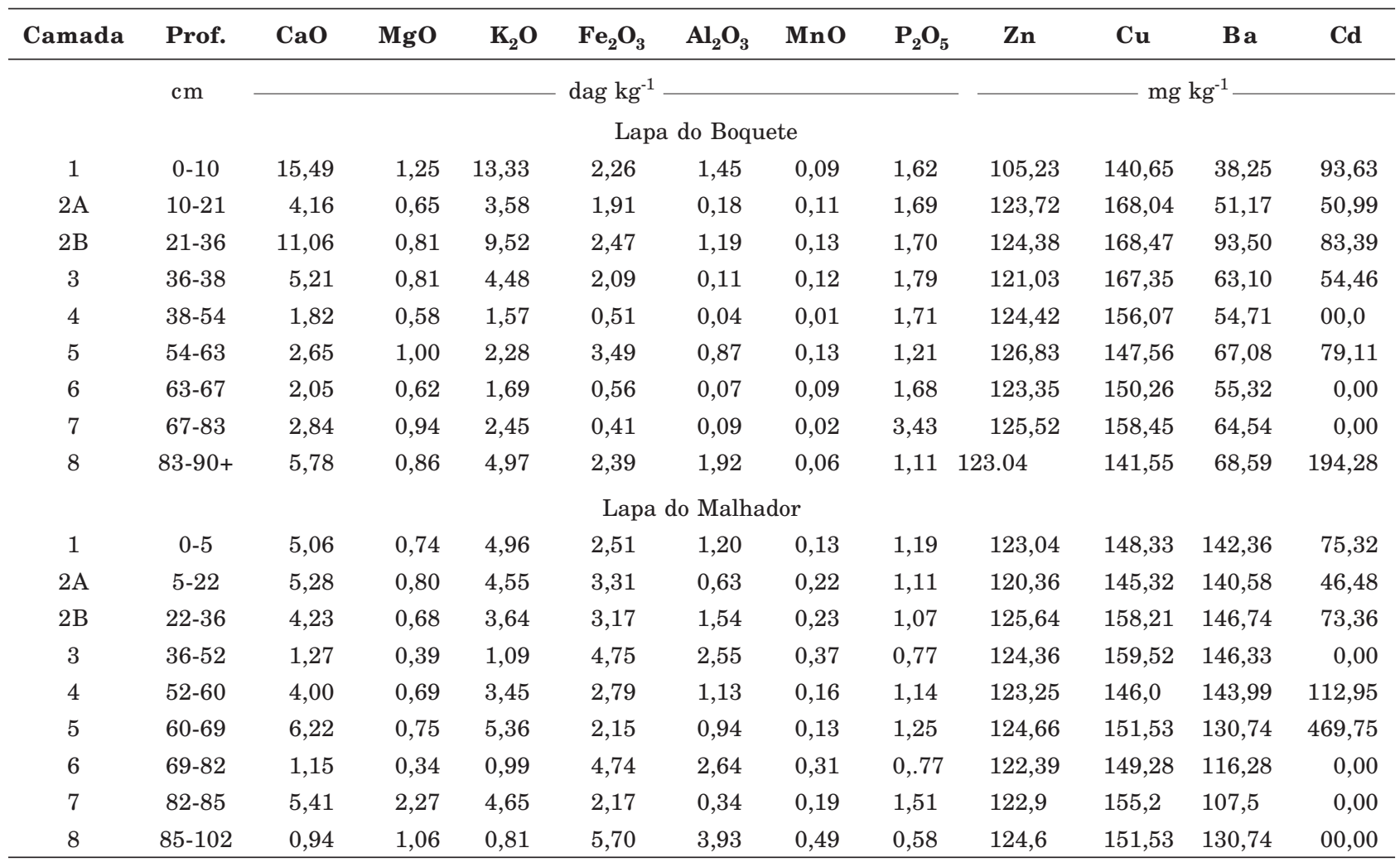

(1) Digestão total da TFSA, conforme o método EPA 3052 (1996).

a gênese dos solos sob abrigos, dentro de um raciocínio pedológico simplificado, que desconsidere as mudanças climáticas e a sazonalidade da ocupação antrópica.

As características encontradas nos solos sob abrigos também se diferenciam das de outros Antropossolos, visto que nestes é possível se distinguirem com facilidade os horizontes onde a atividade antrópica foi mais intensa, daqueles onde predomina a pedogênese natural. Esse fato não foi observado nos solos sob abrigos que apresentaram evidências da antropopedogênese cumulativas ao longo dos perfis estudados. Corrêa (2007) em estudos de solos de sambaquis encontrou dificuldade de separar, no campo ou por meio de análises laboratoriais, os horizontes antrópicos das camadas naturalmente constituídas do solo.

Moura (1998) destacou que a variedade de processos morfogenéticos e morfodinâmicos observados na região teve como consequência grande variedade de depósitos sedimentares nos abrigos que registram a história de evolução da paisagem associada à ocupação humana pretérita. Para exemplificar, nos solos das Lapas do Boquete e do Malhador misturamse materiais provenientes da alteração de concreções ferruginosas, presentes no piso dos abrigos, com sedimentos previamente intemperizados nos compartimentos mais elevados da paisagem e posteriormente transportados por águas pluviais para dentro dos abrigos (Moura, 1998).

\section{Mineralogia}

De maneira geral, são solos que apresentam predominantemente em sua matriz minerais silicatados do tipo 1:1 (caulinita), associados a minerais de argila do tipo 2:1, basicamente illita, que são minerais secundários originários do intemperismo de micas do calcário local (Grupo Bambuí). Os óxidos de Fe presentes foram detectados a partir dos reflexos $0,25\left(d_{110}\right)$ e $0,27 \mathrm{~nm}\left(\mathrm{~d}_{100}\right)$, para hematita, e $0,42 \mathrm{~nm}$ $\left(\mathrm{d}_{101}\right)$, para a goethita (Figuras 2 e 3 ). $\mathrm{O}$ óxido de $\mathrm{Fe}$ predominante nos solos dos abrigos calcários é a hematita, que tem sua gênese favorecida em ambientes mais secos, bem-drenados e com temperaturas mais elevadas, condições que favorecem a desidratação, além de $\mathrm{pHs}$ próximos ou superiores à neutralidade (Schwertmann \& Taylor, 1989). Destacou-se a presença de minerais com atração magnética em quase todas as camadas dos solos dos abrigos, em maior quantidade na fração areia (magnetita), e, em menores proporções, nas demais frações silte e argila (maghemita). A identificação desse material foi feita no campo, por meio de imã manual; posteriormente, no laboratório, foram selecionadas as camadas com maior atração 
magnética, para melhor estudo dessas. Para tanto, foi realizado o tratamento de concentração de óxidos, utilizando $\mathrm{NaOH} 5 \mathrm{~mol} \mathrm{~L}^{-1}$, nas frações argila e areia da camada 2B da Lapa do Malhador, conforme apresentado nas figuras 8 e 9 . Na fração argila, os reflexos $0,251\left(\mathrm{~d}_{113}\right)$ e $0,209 \mathrm{~nm}\left(\mathrm{~d}_{400}\right)$ evidenciaram a presença da maghemita. Já na fração areia, encontrouse a presença da magnetita por meio dos reflexos 0,253 $\left(\mathrm{d}_{113}\right)$ e $0,209 \mathrm{~nm}\left(\mathrm{~d}_{400}\right)$. A atividade antrópica parece ter desempenhado papel-chave na gênese da

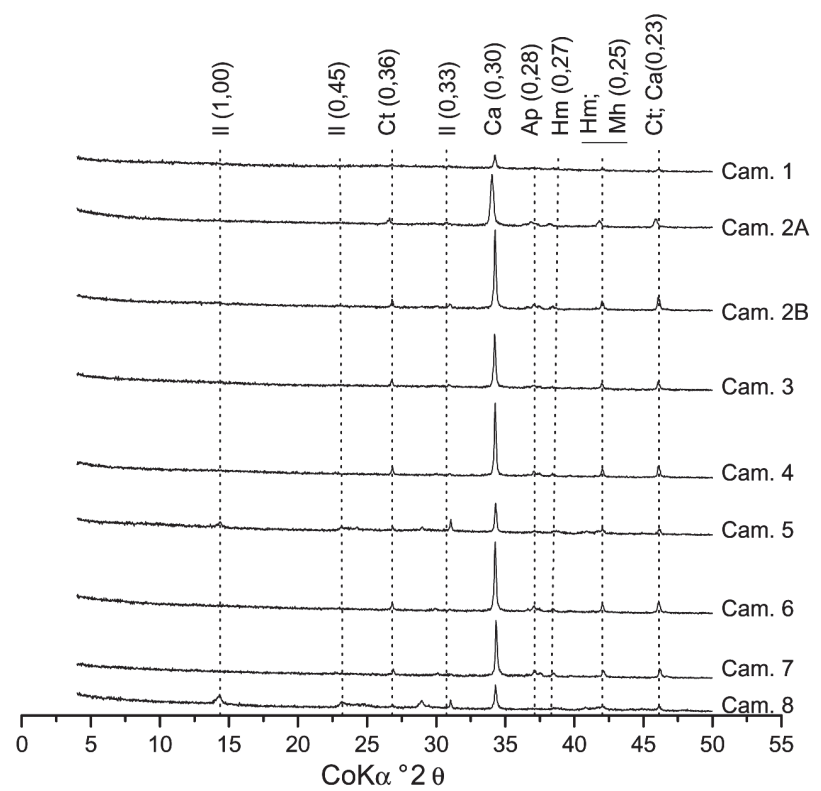

Figura 2. Difratogramas de raios-X da fração argila natural do solo da Lapa do Boquete. Il: illita; Ct: caulinita; Ca: calcita; Hm: hematita; Mh: maghemita; e Ap: apatita.

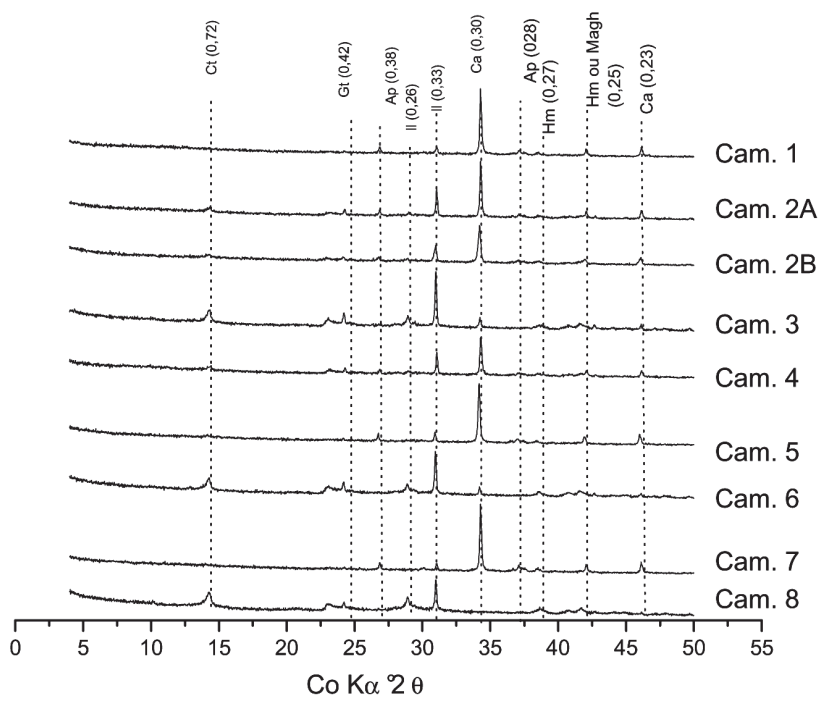

Figura 3. Difratogramas de raios-X da fração argila natural do solo da Lapa do Malhador. Il: illita; Ct: caulinita; Ca: calcita; Hm: hematita; Mh: maghemita; Gt: goethita; e Ap: apatita. maghemita. Segundo Schwertmann \& Taylor (1989), a formação da maghemita se dá a partir de oxidação de partículas de magnetita ou pela transformação de outros óxidos, como goethita ou lepidocrocita, provocada por aquecimento na presença de material orgânico. Nesse contexto, o uso frequente e intenso do fogo com aporte constante de material orgânico nos abrigos contribuiu para a formação de maghemita nos solos estudados.

No estudo mineralógico realizado na fração silte dos solos, observou-se a presença de minerais que

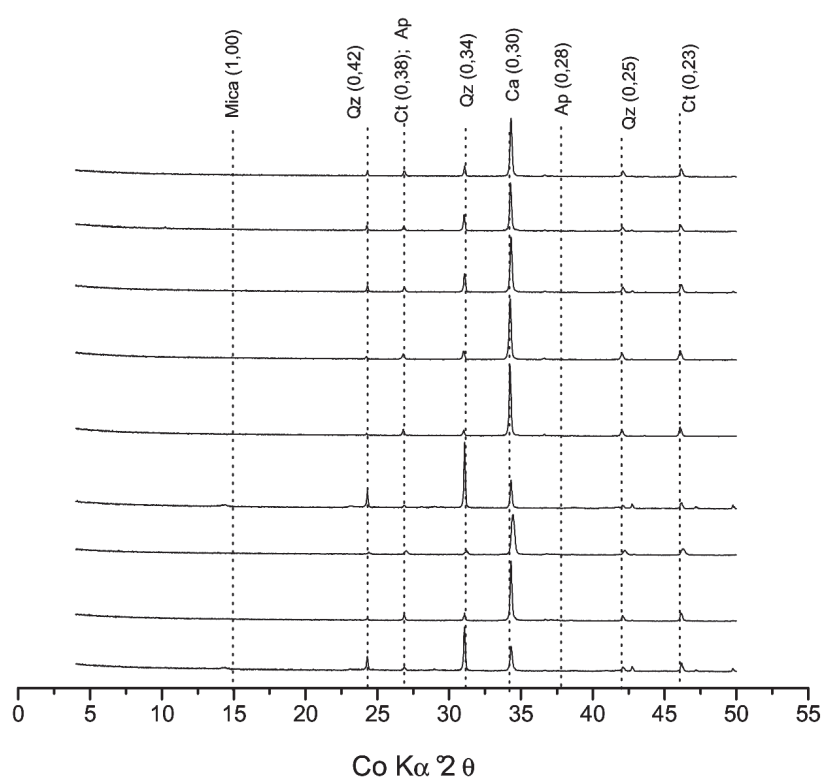

Figura 4. Difratogramas de raios-X da fração silte do solo da Lapa do Boquete. Qz: quartzo; mica; Ct: caulinita; Ca: calcita; e Ap: apatita.

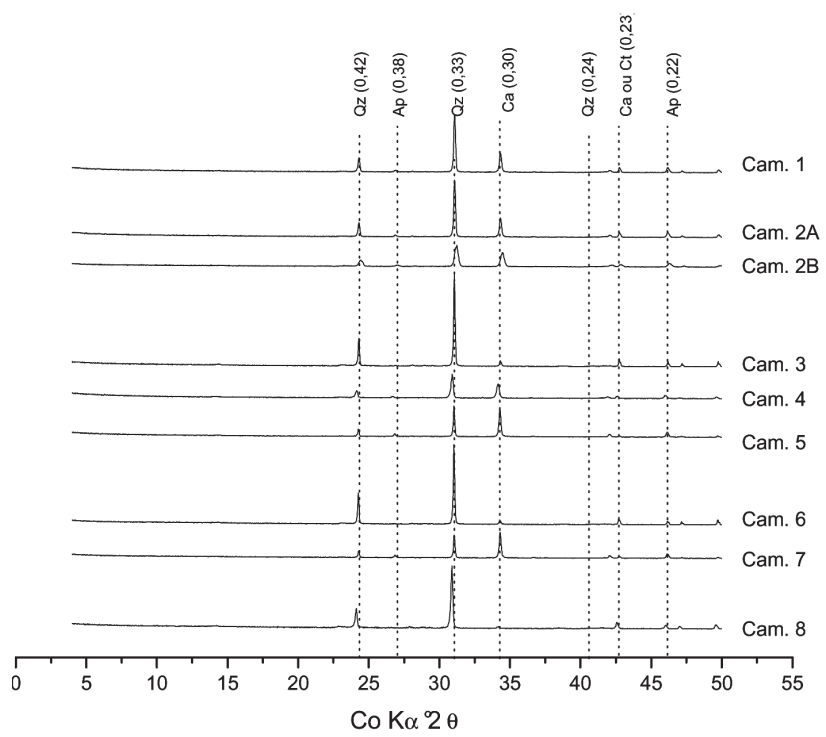

Figura 5. Difratogramas de raios-X da fração silte do solo da Lapa do Malhador. Qz: quartzo; Ct: caulinita; Ca: calcita; Ap: apatita; e Ru: rutilo. 
apresentam maior resistência ao intemperismo químico, como quartzo $\left(\mathrm{SiO}_{2}\right)$ e rutilo $\left(\mathrm{TiO}_{2}\right)$, ao lado de minerais que são mais susceptíveis à alterações químicas, como é o caso da calcita e principalmente da apatita (Figuras 4 e 5), que representam a contribuição antrópica direta na mineralogia dessa fração. Entre os minerais secundários, destaca-se a caulinita. Dessa maneira, a fração silte, que representa um estádio intermediário de alteração do material originário do solo, apresentou certa heterogeneidade do ponto de vista de resistência ao

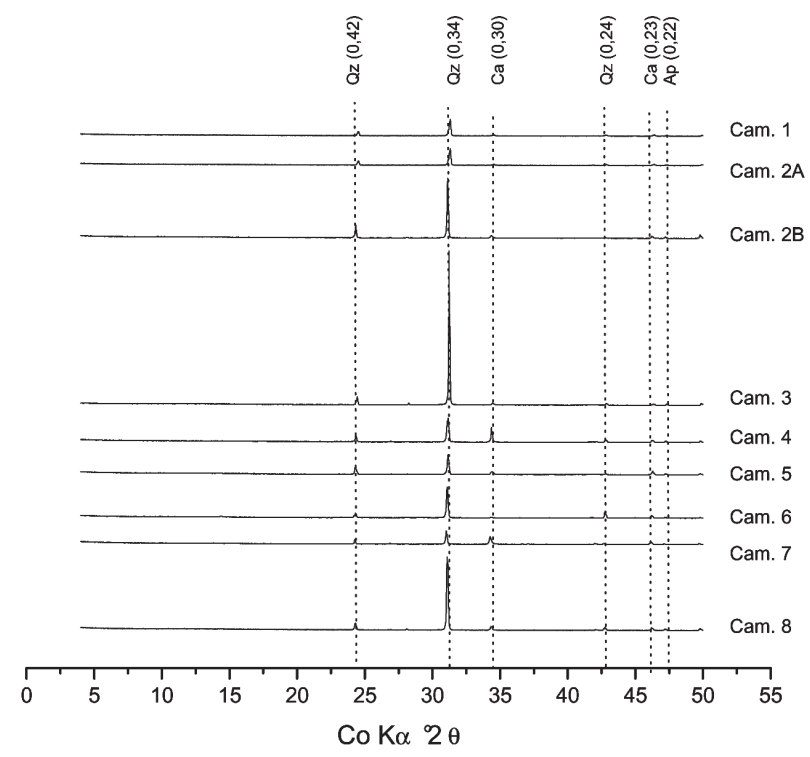

Figura 6. Difratogramas de raios-X da fração areia do solo da Lapa do Boquete. Qz: quartzo; Ct: caulinita; Ca: calcita; e Ap: apatita.

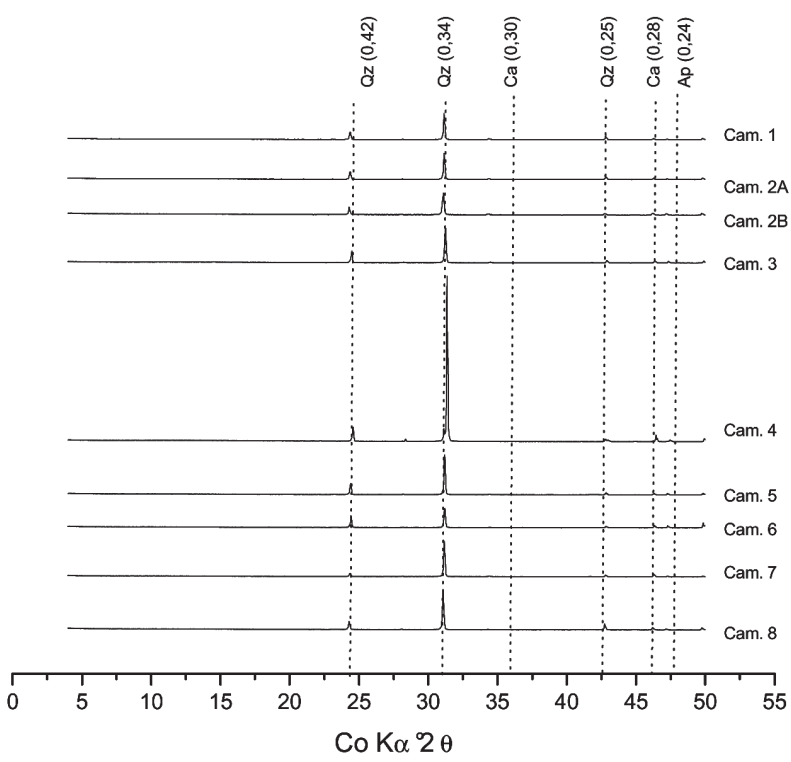

Figura 7. Difratogramas de raios-X da fração areia do solo da Lapa do Malhador. Qz: quartzo; mica; Ct: caulinita; Ca: calcita; e Ap: apatita. intemperismo, visto que coexistem minerais susceptíveis (calcita e apatita) e resistentes (rutilo e quartzo), características marcantes nos solos deste estudo.

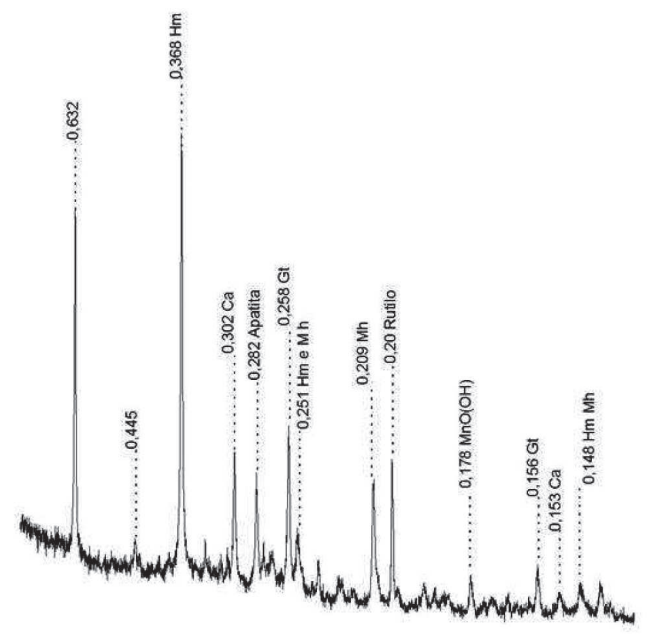

$\begin{array}{lllllllllllllllllllllllll}0 & 5 & 10 & 15 & 20 & 25 & 30 & 35 & 40 & 45 & 50 & 55 & 60 & 65 & 70 & 75 & 80 & 85 & 90\end{array}$

$\mathrm{Co} \mathrm{K} \alpha^{\circ} 2 \theta$

Figura 8. Difratogramas de raios-X da fração argila da camada 2B da Lapa do Malhador, após tratamento com solução de $\mathrm{NaOH} 5 \mathrm{~mol} \mathrm{~L}^{-1}$. Hm: hematita; Mh: maghemita; Ca: calcita; Gt: goethita; Mn: manganita; Ru: rutilo; e Ap: apatita.

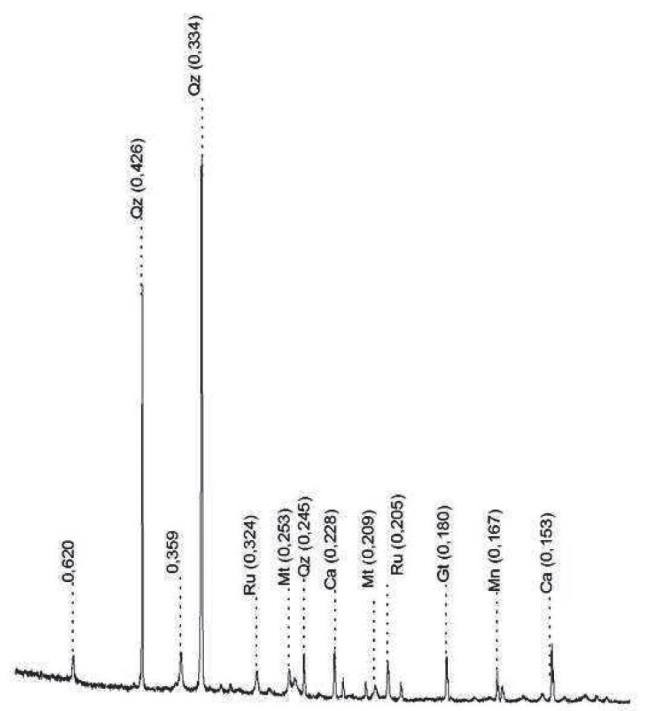

$\begin{array}{llllllllllllllllllll}0 & 5 & 10 & 15 & 20 & 25 & 30 & 35 & 40 & 45 & 50 & 55 & 60 & 65 & 70 & 75 & 80 & 85 & 90\end{array}$

$\operatorname{CoK} \alpha^{\circ} 2 \theta$

Figura 9. Difratogramas de raios-X da fração areia da camada 2B da Lapa do Malhador, após tratamento com solução de $\mathrm{NaOH} 5 \mathrm{~mol} \mathrm{~L}^{-1}$. Mt: magnetita; Ca: calcita; Gt: goethita; Mn: manganita; e Ru: rutilo. 
A fração mais grosseira do solo é composta praticamente dos mesmos minerais encontrados na fração silte, predominando quartzo e calcita, associados às micas (muscovita, principalmente). Como registro mineralógico da presença antrópica nesses solos, foram identificados os reflexos $\left(0,22\left(d_{310}\right)-0,28\left(d_{121}\right)-0,38\right.$ $\left.\left(\mathrm{d}_{002}\right) \mathrm{nm}\right)$, referentes à apatita em todas as frações e praticamente em todas as camadas, demonstrando a importância da preservação de fragmentos ósseos não decompostos. (Figuras 6 e 7).

Em razão da escassez do quartzo em rochas calcárias e da dinâmica de formação dos solos sob abrigos, com intenso aporte de sedimentos alóctones (Moura, 1998), acreditou-se que boa parte do quartzo identificado na fração areia é proveniente do transporte de sedimentos localizados nas partes mais elevadas da paisagem, onde predominam os arenitos da Formação Urucuia, que compõe o topo da geologia regional.

\section{CONCLUSÕES}

1. Os solos antropogênicos sob abrigos calcários são constituídos de camadas diferenciadas, provenientes de fontes alóctones, e denotam a natureza policíclica da deposição. Esses solos foram submetidos a períodos variados de ocupação antrópica pretérita e variações climáticas, expressas por uma variação de atributos químicos e morfológicos nas camadas que os constituem.

2. A atividade antropogênica das populações précolombianas deixou evidências nos atributos físicos do solo como a enorme variação de cor e profundidade entre as camadas. Nos atributos químicos destacaram-se os elevados teores de $\mathrm{P}$ e carbono orgânico. Já nos aspectos mineralógicos, essa atividade é evidenciada pela presença do mineral apatita, identificado em todas as frações e camadas dos solos estudados.

3. Os solos estudados apresentaram elevada atração magnética a imãs manuais. Portanto, o reflexo $0,25 \mathrm{~nm}\left(\mathrm{~d}_{113}\right)$ identificado na fração argila de praticamente todas as camadas que constituem esses solos denota não só a presença de hematita, como também de maghemita; a gênese da maghemita nesse ambiente está associada à atividade antropogênica, por meio da exposição contínua de óxidos de ferro a elevadas temperaturas, por uso recorrente de fogo nos abrigos.

4. Os solos estudados apesar de exporem característica que comprovam a antropopedogênese e de conterem camadas que se enquadram dentro dos critérios estabelecidos para horizontes antrópicos do Sistema Brasileiro de Classificação de Solos (SiBCS), evidenciaram singularidades que os tornam difíceis de enquadramento taxonômico.

\section{LITERATURA CITADA}

COMPANHIA DE TECNOLOGIA DE SANEAMENTO AMBIENTAL - CETESB. Relatório de estabelecimento de valores orientadores para solos e águas subterrâneas no Estado de São Paulo. São Paulo, 2005. 73p.

CORRÊA, G.R. Caracterização pedológica de arqueoantropossolos no Brasil: sambaquis da região dos Lagos (RJ) e terras pretas do índio na região do baixo rio Negro/ Solimões (AM). Viçosa, MG, Universidade Federal de Viçosa, 2007. 115p. (Dissertação de Mestrado)

EMPRESA BRASILEIRA DE PESQUISA AGROPECUÁRIA EMBRAPA. Manual de métodos de análise de solo. 2.ed. Rio de Janeiro, Centro Nacional de Pesquisa de Solos, 1997. 209p.

EPA 3052. Microwave assisted acid digestion of siliceous and organically based matrices. Washington, Revision, December, 1996. 20p.

FAO-ISSS-ISRIC. World reference base for soil resources. A framework for international classification correlation and communication. Roma, 2006. 127p.

KÄMPF, N. \& KERN, D.C. O Solo como registro da ocupação humana pré-histórica na Amazônia. In: TORRADOVIDAL, P.; ALLEONI, L.R.F.; COOPER, M. \& SILVA, A.P., eds. Tópicos em ciência do solo. Viçosa, MG, Sociedade Brasileira de Ciência do Solo, 2005. v.4. p.207320.

KÄMPF, N.; WOODS, W.I.; SOMBROEK, W.; KERN, D.C. \& CUNHA, T.J.F. Classification of Amazonian Dark Earths and other ancient antropic soils. In: LEHMANN, J.; KERN, D.C.; GLASER, B. \& WOODS, W.I., eds. Amazonia Dark earths. Origin, properties and management. Dordrecht, Kluwer Academic Publishers, 2003. p.77-102.

KELLY, J.; LAMBERT, M.J. \& TURNER, J. Available phosphorus forms in forest soils and their possible ecological significance. Commun. Soil Ci. Plant Anal., $14: 1217-1234,1983$

KERN, D.C. \& KÄMPF, N. Antigos assentamentos indígenas na formação de solos com Terra Preta Arqueológica na região de Oriximiná, Pará. R. Bras. Ci. Solo, 13:219-225, 1989.

KERN, D.C.; D'AQUINO, G.; RODRIGUES, T.E.; FRAZÃO, F.J.L.; SOMBROEK, W.; MYERS, T.P. \& NEVES, E.G. Distribution of amazonian dark earths in the Brazilian Amazon. In: LEHMANN, J.; KERN, D.C.; GLASER, B. \& WOODS, W.I., eds. Amazonia dark earths. Origin, properties and management. Dordrecht, Kluwer Academic Publishers, 2003. p.51-75.

LIMA, H.N.; SCHAEFER, C.E.G.R.; MELLO, J.W.V.; GILKES, R.J. \& KER, J.C. Pedogenesis and pre-Colombian land use of "Terra Preta Anthrosol" ("Indian Black earth") of Western Amazonia. Geoderma, 100:1-17, 2002.

MOURA, M.T.T. Evolução do Sítio Arqueológico Lap do Boquete na Paisagem do Vale do Rio Peruaçu-Januária, MG. São Paulo, Departamento de Geografia. FFLCH/USP, 1998. 208p. (Dissertação de Mestrado) 
NEVES, W.; BLUM, M.; HÜBBE, M.; WESOLOWSKI, V. \& BARTOLOMUCCI, R. Os remanescentes ósseos humanos do Vale do Rio Peruaçu, Minas Gerais. Cura, caracterização geral e afinidades biológicas. Arq. Museu Hist. Nat. Jardim Bot. UFMG, 19:187-230, 2009.

NOVAIS, R.F. \& SMYTH, T.J. Fósforo em solo e planta em condições tropicais. Viçosa, MG, Universidade Federal de Viçosa, 1999. 399p.

OLIVEIRA, C.V. Atributos químicos, mineralógicos e micromorfológicos, gênese e uso de solos do Projeto Jaíba, norte de Minas Gerais. Viçosa, MG, Universidade Federal de Viçosa, 1999. 161p. (Tese de Doutorado)

PABST, E. Critérios de distinção entre Terra Preta e Latossolo na região de Belterra e os seus significados para a discussão pedogenética. Bol. Museu Paraense Emílio Goeldi. Sér. Antropol., 7:5-19, 1991.

PROUS, A. Arqueologia brasileira. Brasília, Universidade de Brasília, 1992. 613p.

PROUS, A. Relatório preliminar do Plano de Manejo do Parque Nacional Cavernas do Peruaçu. Meio Antrópico. 2003. p.1410-1476.
RUIZ, H.A. Incremento da exatidão da análise granulométrica do solo por meio da coleta da suspensão (silte + argila). R. Bras. Ci. Solo, 29:297-300, 2005.

SCHWERTMANN, U. \& TAYLOR, R.M. Iron oxides. In: DIXON, J.B. \& WEED, S.B., eds. Minerals in soil environments. 2.ed. Madison, Soil Science Society of America, 1989. p.789-824.

SILVEIRA, I.M.; KERN, D.C. \& QUARESMA, H.D. Populações tradicionais. In: LISBOA, P.L.B., org. Caxiuanã, populações tradicionais, meio físico e diversidade biológica. Belém, 2002. 734p.

SOIL SURVEY STAFF. Keys to soil taxonomy. 8.ed. Washington, United States Departament of Agriculture Natural Resources Conservation Service, 1998. 328p.

WOODS, W.I. Development of Anthrosol research. In: LEHMANN, J.; KERN, D.C.; GLASER, B. \& WOODS, W.I., eds. Amazonia dark earths. Origin, properties and management. Dordrecht, Kluwer Academic Publishers, 2003. p. 3-14.

YEOMANS, J.C. \& BREMNER, J.M. A rapid and precise method for routine determination of organic carbon in soil. Commun. Soil. Sci. Plant Anal., 19:1467-1476, 1988. 